\title{
Assessment of xanthan gum and xanthan-g-silica derivatives as chemical flooding agents and rock wettability modifiers
}

\author{
Ahmed Ashraf Soliman ${ }^{1, *}$, Abdelaziz Nasr El-hoshoudy ${ }^{1,2}$, and Attia Mahmoud Attia ${ }^{1,3}$ \\ ${ }^{1}$ Department of Petroleum Engineering, Faculty of Engineering, British University in Egypt (BUE), Elshorouk City, \\ Cairo 11837, Egypt \\ ${ }^{2}$ Department of Production, Egyptian Petroleum Research Institute, Naser City, Cairo 11727, Egypt \\ ${ }^{3}$ Faculty of Energy and Environmental Engineering, British University in Egypt (BUE), Elshorouk City, Cairo 11837, Egypt
}

Received: 22 August 2019 / Accepted: 20 January 2020

\begin{abstract}
Currently, biomolecules flooding in the underground reservoirs acquires sustainable interest owing to their availability and eco-friendly properties. The current study reported chemical displacement by xanthan gum as well as xanthan $/ \mathrm{SiO}_{2}$ and xanthan grafted with vinylsilane derivatives. Chemical characterization evaluated by traditional spectroscopic methods. Investigation of fluids response to reservoir environment assessed through rheological performance relative to shearing rate, ionic strength, and thermal stability. A sequence of flooding runs generated on 10 sandstone outcrops with different porosity and permeabilities. Core wetness assessed through relative permeability curves at different water saturation. The flooding tests indicate that grafting of the silica derivative overcome the shortage of xanthan solution in flooding operations relative to the reservoir conditions. The ability of the flooding solutions to alter rock wettability explored through relative permeability curves at different water saturation. The results reveal that the synthesized composite was a promised agent for enhancing oil recovery and profile conformance.
\end{abstract}

$\begin{array}{ll}\text { Nomenclature } \\ \mu & \text { The solution viscosity }(\mathrm{CP}) \\ \mu_{0} & \text { Pure solvent viscosity }(\mathrm{CP}) \\ \eta & \text { Intrinsic viscosity }\left(\mathrm{dLg}^{-1}\right) \\ K_{\mathrm{h}} & \text { Huggins constant }\left(\operatorname{dimensionless~quantity)~}_{C} \quad \text { Polymer concentration }\left(\mathrm{dLg}^{-1}\right)\right. \\ M_{\mathrm{w}} & \text { Molecular weight }\left(\mathrm{g} / \mathrm{mol}^{-}\right) \\ \gamma & \text { Shear rate }\left(\mathrm{s}^{-1}\right) \\ a & \text { Flow consistency }\left(\mathrm{Pa} \mathrm{s} \mathrm{s}^{-\mathrm{n}}\right) \\ n & \text { Flow behavior index }(\text { dimensionless parameter }) \\ \xi & \text { Adsorbed layer thickness }(\mu \mathrm{m}) \\ r & \text { Average pore radius }(\mu \mathrm{m}) \\ R_{\mathrm{ff}} & \text { Residual resistance factor } \\ R_{\mathrm{f}} & \text { Resistance factor } \\ M & \text { Mobility ratio }(\text { dimensionless factor }) \\ \text { Slug size } & \text { Slug concentration }(\mathrm{g} / \mathrm{L}) / \text { pore volume }(\mathrm{cc}) \\ \text { Slug } & \text { Slug concentration }(\mathrm{lb}) / \text { recovered oil }(\mathrm{bbl}) \\ \text { efficiency } & \\ \overline{S_{\mathrm{w}}} & \text { The average water saturation } \\ S_{\mathrm{wi}} & \text { The initial water saturation }\end{array}$

* Corresponding author: ahmed.abdelhafez@bue.edu.eg

$\begin{array}{ll}\text { ED } & \text { Displacement efficiency } \\ K_{\text {ro }} & \text { Oil relative permeability (md) } \\ K_{\text {rw }} & \text { Water relative permeability (md) } \\ F_{\mathrm{w}} & \begin{array}{l}\text { Fractional flow of water (dimensionless } \\ \end{array} \\ & \text { quantity) }\end{array}$

\section{Introduction}

Nowadays, attention to chemical flooding grows up incrementally in the developing countries on the academic and technological scale due to increased energy consumption (Bera and Belhaj, 2016). Several efforts implemented to recover entrapped oil through improvement of sweeping efficiency (AfzaliTabar et al., 2017). Chemical processing by polymer flooding has a significant potentiality to recover about $35 \%$ of original oil in place after secondary water displacement (Hu et al., 2018). Polymer flooding either by conventional polymers, polymer/inorganic particles or by polymers-grafted vinyl monomers rely on three main strategies including; (1) improvement of the sweeping efficiency through mobility ratio controlling (Bai et al., 2018); (2) selective reduction of water phase relative permeability (Maghzi et al., 2014); (3) performing viscoelastic flow in the 
porous media (Kang and Zhang, 2013). On the reservoir scale, nanomaterials serve as wettability modifiers, interfacial tension reducing agents, and adsorbents on rock surface to minimize the adsorbate amount during flooding process (Bera and Belhaj, 2016; Zargartalebi et al., 2015). One of the widely implemented nanomaterials in oil field processing is the hydrophilic silica nanoparticles with different geometries and crystal structure (Zargartalebi et al., 2015). Ordered molecular sieved silica-based materials have uniform pores $<50 \mathrm{~nm}$, high surface area, abundant hydroxyl groups and narrow pore size distribution (Kovalchuk et al., 2005), so used in many applications involving catalysis, energy storage, and environmental remediation (Wang et al., 2016). Moreover, it displays adsorption criteria at the oil/brine/rock interfaces, which in turn producing shear and wetting action on the crude oil layer (Maghzi et al., 2014). Several reports stated the synthesis of different ordered mesoporous silicates and their application in improved oil recovery as rheology and wettability modifiers, or emulsion stabilizers as stated elsewhere (Bera and Belhaj, 2016; Hu et al., 2017). On the other hand, xanthan is a bacteriological water-soluble polysaccharide produced by Xanthomonas bacterium species through the biofermentation process, with a high molecular weight $(>2 \times$ $10^{6} \mathrm{~g} / \mathrm{mol}$ ) (Kumar et al., 2017). Solutions of xanthan gum exhibit shear thinning (Pseudoplastic) behavior (Suh et al., 1990) and drag reducing criteria under subsurface environments (Zhong et al., 2013) in addition to their higher viscosity, and ease penetration into low permeability zones (Zhong et al., 2013) so preferred in the underground chemical flooding processes (Kumar et al., 2017). Theoretically, biopolymers are preferred rather than synthetic polymers owing to their availability, efficient biodegradability, and eco-friendly properties (Badwaik et al., 2016). On the industrial scale, xanthan solutions, as well as hydrolyzed polyacrylamides, suffer from chain degradation due to high ionic strength, bacterial attack, and thermal degradation under harsh reservoir environment (Li et al., 2018). Consequently, amendment to their rheological response conducted by mixing with inorganic silica nanoparticles (Maurya et al., 2017) or grafting with vinylsilane derivative to boost the shearing resistance, mechanical stress, robust thermal and salinity response, as well as toughness and anti-polyelectrolyte properties (Kumar and Sharma, 2018), through the formation of network assembly between nanoparticles and polymer architecture (Bera and Belhaj, 2016). Moreover, hybridization of the polymer backbone with thermosensitive pendant groups enhance polymeric chains stability (Liu et al., 2017; Pu et al., 2015). Inoculation of silane derivatives through biopolymer matrix reduce particles agglomeration and retard macromolecules propagation during polymerization process owing to nanoscale nucleation effect (El-Hoshoudy, 2018b). Many researchers stated the grafting of xanthan with vinyl monomers through typical free radical emulsion polymerization. Polymerized nanocomposites characterized by a dispersion of nanoparticles through polymer architecture so, exhibit preferred properties rather than conventionally filled polymers (El-Hoshoudy et al., 2016) and can be considered as a reasonable Enhanced Oil Recovery (EOR) agents due to their capability to reduce interfacial tension and alter wetting properties (Shamilov et al., 2017). Application of polymer-g-nanoparticles have been reported previously, and comprising the preparation of $\mathrm{TiO}_{2}, \mathrm{SiO}_{2}, \mathrm{ZnO}$ nanoparticles and their copolymerization/grafting with vinyl monomers for alteration of the sandstone rock wettability, and improvement of oil and water flow since they can flow through unswept zones, and enhance the sweeping effectiveness. This study reports about a facile synthesis of $\mathrm{SiO}_{2}$ nanoparticles through Stöber method then mixing with xanthan gum. Moreover, xanthan gum will be grafted with methylbis(trimethylsilyloxy)vinylsilane through free radical copolymerization. Interpenetrating xanthan network with vinylsilane monomers enhances its physicochemical and rheological properties (Pandey and Mishra, 2011). Rheological criteria screened at simulated reservoir environment related to mechanical shearing, salinity resistance, and thermal degradation. A sequence of flooding runs performed through sandstone cores using different flooding solutions including xanthan gum (XG), xanthan gum $/ \mathrm{SiO}_{2}$ physical mixture and xanthan gum-grafted-silica composite (XG-g-silica). The incremental oil recovery and relative permeability curves investigated at different pore volumes and water saturation. The capability of the flooding solutions to alter rock wettability investigated through relative permeability curves. To the best of our knowledge, scarce reports deal with the application and modification of biopolymers composites in the field of EOR. Consequently, this work establishes a complementary foundation in the modification and implementation of xanthan biopolymer in oil field processing through enhancing recovery factor and altering wettability of sandstone rocks.

\section{Experimental analysis}

\subsection{Materials}

Sodium Dodecyl Sulfate (SDS $\geq 99 \%$ ); ammonium hydroxide solution $\geq 99.99 \%$; Hexadecyltrimethylammonium bromide ( $\mathrm{CTAB} \geq 99 \%)$; Hydrochloric acid (37\%); Tetraethylorthosilicate (TEOS, 99.99\%); Commercial xanthan gum used without further purification; Methylbis (trimethylsilyloxy) vinylsilane (IUPAC name; 1,1,1,3, 5,5,5-heptamethyl-3-vinyltrisiloxane $\sim 98 \%$ ); potassium persulfate "KPS" $\left(\mathrm{K}_{2} \mathrm{~S}_{2} \mathrm{O}_{8} ; \geq 99 \%\right.$; acetone $\geq 97 \%$; methanol $\geq 97 \%$. All reagents and materials supplied by Merck and used without additional treatment. All solutions were organized using double distilled (dd) water.

\subsection{Synthesis of nano- $\mathrm{SiO}_{2}$ and XG-g-silica composite}

$\mathrm{SiO}_{2}$ synthesis performed according to the Stöber method with some modification (Stöber et al., 1968; Wang et al., 2016). Typically, $2.0 \mathrm{~g}$ of CTAB was dissolved in $120 \mathrm{~g}$ of dd water until complete solubility. Then, add $8.0 \mathrm{~mL}$ of concentrated ammonical solution (33.0 wt \%). After that, add $10 \mathrm{~mL}$ of TEOS drop wisely under continuous stirring at $200 \mathrm{rpm}$ for $40 \mathrm{~min}$, where a uniformly colloidal solution formed progressively during TEOS addition and continue 
stirring overnight. The product was filtrated and washed with deionized water and ethanol, and then vacuum dried at $80{ }^{\circ} \mathrm{C}$ for $17 \mathrm{~h}$. Ordered mesoporous silica obtained by calcination at $550{ }^{\circ} \mathrm{C}$ for $4 \mathrm{~h}$. Synthesis of XG-g-silica composite carried out according to the following procedure. In a $500 \mathrm{~mL}$ Erlenmeyer three-neck flask supplied with a condenser, thermometer, and nitrogen source dissolve $1.3 \mathrm{~g}$ of SDS in $350 \mathrm{~mL}$ of dd water, then add $3.0 \mathrm{~g}$ of xanthan gum and stir vigorously until complete dissolution. Under nitrogen flooding add $0.06 \mathrm{~g}$ of 1,1,1,3,5,5,5-heptamethyl3 -vinyltrisiloxane and $0.4012 \mathrm{~g}$ of KPS under continuous stirring and adjust the temperature at $65{ }^{\circ} \mathrm{C}$. The reaction continues for $4 \mathrm{~h}$, then cooled down to room temperature. XG-g-silica composite precipitated by dissolving in distilled water, ethanol, acetone, and then Soxhlet extraction with acetone for $5 \mathrm{~h}$ at $50{ }^{\circ} \mathrm{C}$. The chemical reaction as illustrated in Scheme 1 (Supporting Information) is initiated by the formation of the propagating sites on xanthan gum with the aid of initiator followed by their copolymerization with activated vinyl monomers through a typical free radical polymerization reaction. The ionic composition of the saline solutions used in rheological measurements and flooding experiments is provided in Supporting Information.

\subsection{Measurement and characterization}

FTIR spectroscopy collected on American FTS-3000 spectrophotometer using $\mathrm{KBr}$ pellets in the range of 500-4000 $\mathrm{cm}^{-1}$. NMR analysis obtained with a Bruker spectrometer. The peaks logged after 32 shots, using deuterium oxide $\left(\mathrm{D}_{2} \mathrm{O}\right)$ solvent. The spectrum processed with Mnova software for peaks identification (El-hoshoudy et al., 2019). Transmission Electron Microscopy (TEM) images monitored on JEM-2100F high-resolution transmission electron microscope operating at $200 \mathrm{kV}$. The samples were distributed in ethanol and then dried on the copper $(\mathrm{Cu})$ grid (Wang et al., 2016). Thermal Gravimetric Analysis (TGA) carried out on TA-instrument SDT thermoanalyzer under nitrogen flooding at $50 \mathrm{~mL} / \mathrm{min}$. About $5-7 \mathrm{mg}$ of the sample was vacuum dried at $60^{\circ} \mathrm{C}$, then subjected to thermal analysis. Molecular weight determined through estimation of intrinsic viscosity in $0.1 \mathrm{~mol} \mathrm{NaCl}$ at $25.0^{\circ} \mathrm{C}$ with a Ubbelohde capillary viscometer through the dilution extrapolation method (El-Hoshoudy et al., 2016; Hu et al., 2018). Brookfield programmable DV-II ${ }^{+}$ rheometer used for measurement of the apparent viscosity related to mechanical shearing, saline concentration, and the temperature effect. All spectroscopic characterization and analysis are provided in Supporting Information.

\subsection{Core physical properties and flooding experiments}

Flooding runs performed through core flooding system on sandstone cores that considered as a clastic sedimentary rock of high porosity and permeability due to the presence of quartz and/or feldspar minerals in its constituents (Boggs and Boggs, 2009; McGeary et al., 2001; Porter, 1987). Core samples subjected to Soxhlet extraction with toluene, followed by vacuum drying at $80^{\circ} \mathrm{C}$ for $24 \mathrm{~h}$. After that, the cores immersed into desiccator filled with a brine

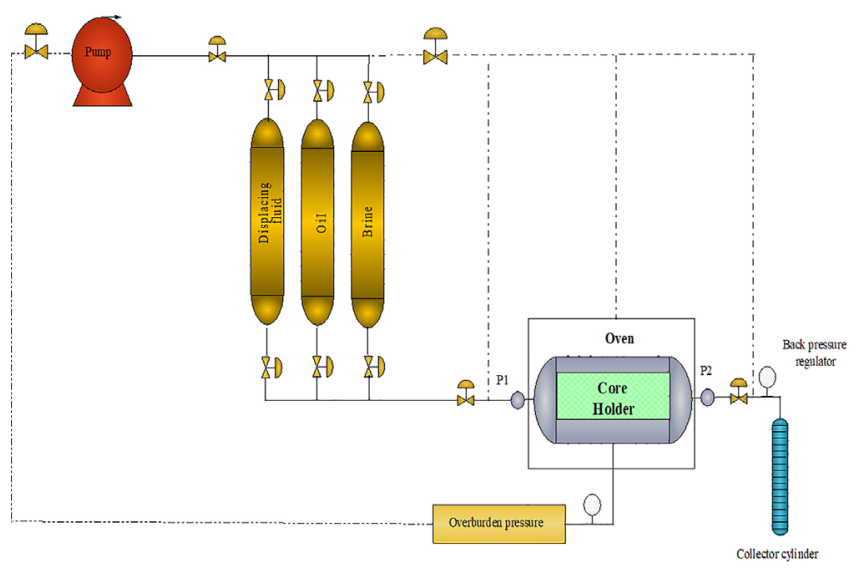

Fig. 1. Schematic diagram for flooding system.

solution of $20 \mathrm{~g} / \mathrm{L}$ salinity for one day to assure complete brine saturation (Bai et al., 2018). The physical properties and geometries of the 10 cores and flooding conditions are reported in Supporting Information. The cores porosity was calculated using imbibition method in which the dry weight was reported. After that, the cores were soaked in formation water until they were fully saturated, and weight after saturation was reported. The bulk volume calculated through Vernier caliper, which used to measure the length and diameter of cylindrical cores. The cores were located inside the core holder and soaked with a single liquid phase (water/oil), then single cylinder displacement-pump operated to allow fluid flow through the core, where the readings of flow rate and pressure difference recorded as a function of time (Salehi et al., 2014). Saturated cores were placed inside the core holder where the flooding experiment performed at room temperature and a constant injection rate of $3.0 \mathrm{cc} / \mathrm{min}$. A single cylinder pump injected the crude oil until ejection of brine ceased off (El-Hoshoudy, 2018b; El-Hoshoudy and Desouky, 2018; El-Hoshoudy et al., 2018). The displaced brine represents the initial oil in place $\left(V_{\mathrm{oi}}\right)$ and the remaining brine inside the core represents the connate water saturation $\left(S_{\mathrm{wc}}\right)$. After that, the core flooded with brine solution until oil ceased off (oil cut $<1 \%$ ). The volume of oil, water, as well as displacing time, and pressure drop recorded at each injected pore volume (Fig. 1).

\section{Results and discussion}

\subsection{Rheological properties}

\subsubsection{Intrinsic viscosity and molecular weight}

Intrinsic viscosity determined from Huggins formula (Goldberg et al., 1947) as indicated in equation (1). Plotting specific viscosity $\left[=\left(\mu-\mu_{0}\right) / \mu_{0}\right]$ versus concentration $(c)$ on the Cartesian scale then extrapolating the curve to infinite dilution (zero concentration) give intrinsic viscosity value which equates to the slope of the line (Hu et al., 2018). The polymer molecular weight determined by Mark-Houwink relation in $0.1 \mathrm{M} \mathrm{NaCl}$ at $25^{\circ} \mathrm{C}$ (Chiantore, 2005) as shown 
Table 1. Computed intrinsic viscosity and molecular weight of XG-g-silica composite.

\begin{tabular}{lcccc}
\hline$C\left(\mathrm{gdL}^{-1}\right)$ & {$\left[\left(\mu-\mu_{0}\right) / \mu_{0}\right]$} & $\frac{\left[\left(\mu-\mu_{0}\right) / \mu_{0}\right]}{C}$ & $\eta\left(\mathrm{dLg}^{-1}\right)$ & $M_{\mathrm{w}}(\mathrm{g} / \mathrm{mol})$ \\
\hline 0.5 & 90.0 & 180.98 & 133.24 & $8.40 \times 10^{6}$ \\
0.4 & 70.0 & 173.72 & & \\
0.3 & 50.0 & 164.70 & & \\
0.2 & 30.0 & 153.92 & & \\
0.1 & 14.3 & 141.38 & & \\
\hline
\end{tabular}

in equation (2). The calculated intrinsic viscosity, as well as molecular weight, are summarized in Table 1 and Figure 2:

$$
\begin{gathered}
\frac{\left[\left(\mu-\mu_{0}\right) / \mu_{0}\right]}{C}=[\eta]+k_{\mathrm{h}}[\eta]^{2} C, \\
{[\eta]=0.0000017\left(M_{\mathrm{w}}\right)^{1.14} .}
\end{gathered}
$$

\subsubsection{Mechanical degradation and shear rate effect}

Mechanical deformation occurs when the polymer molecules subjected to a high shear rate at low permeability of reservoir rock, and result in a reduction of mobility ratio by $80 \%$ (Maerker, 1975). By shear applying, the fluids perform 1 of the 4 distinct rheology profiles; thixotropic, Newtonian, non-Newtonian, and dilatant. In this section, the shearing action of the displacing fluids evaluated through different concentrations $(1.0,1.5$, and $2.0 \mathrm{~g} / \mathrm{L})$ at $25^{\circ} \mathrm{C}$ as depicted in Figure 2. It is apparent that all fluids exhibit shear thinning behavior as the viscosity decrease by shearing action increase (Pu et al., 2015) due to the chain scission then tend to be stable, so they belong to pseudoplastic profile (nonNewtonian fluid; Ye et al., 2013). Viscosity related to shear rate by power-law relation (Xu et al., 2011) as shown in equation (3):

$$
\mu=a \gamma^{-n}
$$

shear thinning nature controlled by $n$-value, as increasing of $n$-values above zero $(n>0)$, indicate that the fluids exhibit shear thinning effect (El-Hoshoudy, 2018a). The calculated $n$-values of the three displacing fluids at a concentration of $2.0 \mathrm{~g} / \mathrm{L}$ (Fig. 3d) are summarized in Table 2. It's clear that viscosity reduction in XG-g-silica composite and $\mathrm{XG} / \mathrm{SiO}_{2}$ is lesser than xanthan gum, also XG-g-silica composite exhibit the highest ( $K$ and $n$ ) values, which indicate that insertion of the silica increase elasticity of composite owing to the hydrogen bonding formation between silanol groups and hydroxyls of xanthan, which give rise to elastic structure with high shear degradation resistance. Moreover, silica particles act as a physical cross-linker embedded through polymer chains, which provide enough roughness against chains scission and mechanical degradation, so improve rheological properties of composite solutions (AfzaliTabar et al., 2017). These results accomplished with Maghzi et al. (2013) who showed the same trend when $\mathrm{SiO}_{2}$ nanoparticles used as a rheology modifier in polymers solutions.



Fig. 2. Intrinsic viscosity relative to polymer concentration.

\subsection{3 lonic strength response}

Petroleum reservoirs have different degrees of salinity ranged from high to moderate salt content (Ahmadi and Shadizadeh, 2018). During polymer flooding, xanthates solutions greatly affected by the high ionic strength of the formation water (Zhong et al., 2013). Effect of salinity on displacing fluids investigated at different slug concentrations $(1.0,1.5$, and $2.0 \mathrm{~g} / \mathrm{L})$ and different salinities (3.5, $10.0,15.0$, and $20.0 \mathrm{~g} / \mathrm{L}$ ) at room temperature as shown in Figures 4a-4c. Viscosity rises up with polymer concentration increase due to intensified intermolecular association (Zhong et al., 2013). Viscosity reduction and degradation of xanthan gum by incremental salt addition, resort to the dipole ionic interaction among the formation water cations $\left(\mathrm{Ca}^{+2}, \mathrm{Na}^{+}\right)$and oxygen $\left(\mathrm{COO}^{-}\right)$of ester in xanthan polymer chains (Maghzi et al., 2014), consequently the elongated molecules converted into helical structural conformation with reduced hydrodynamic volume resulting in viscosity falling down ( $\mathrm{Hu}$ et al., 2018). Figure 4d compares salinity resistance of the three fluids at a slug 


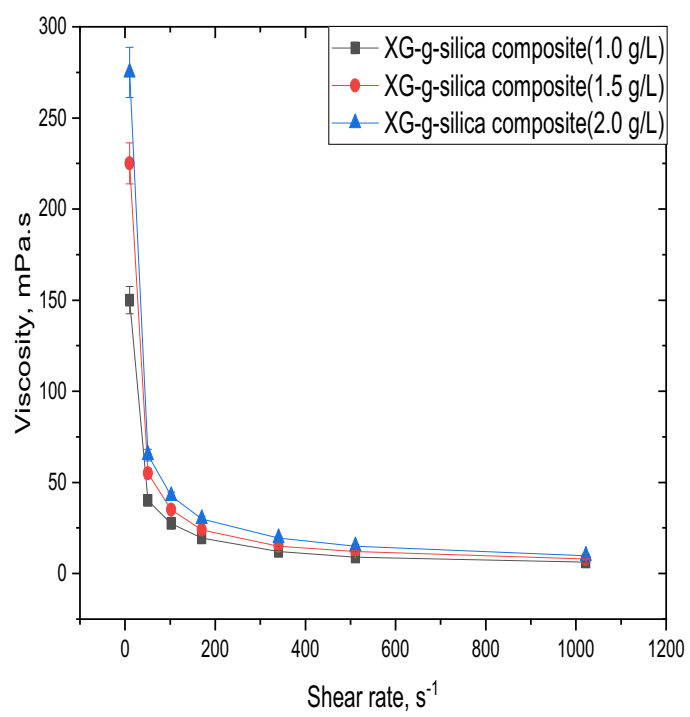

(a)

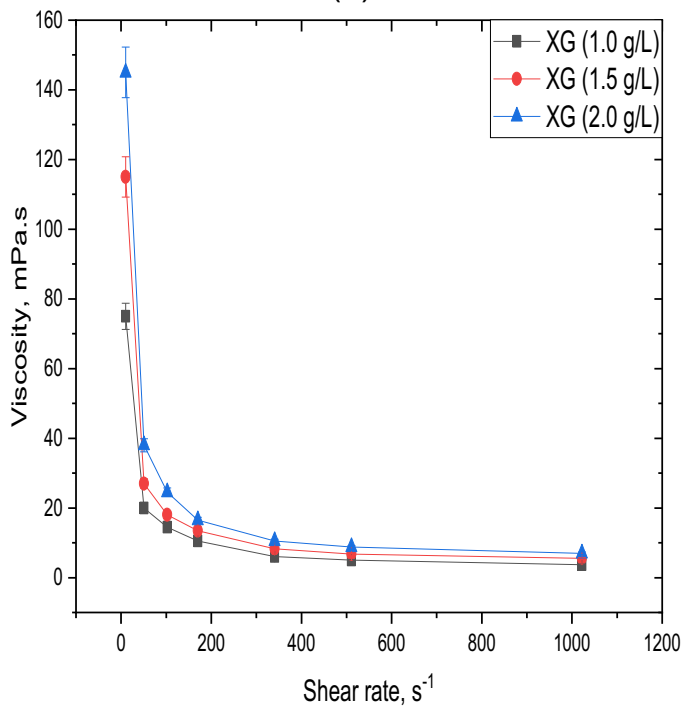

(c)

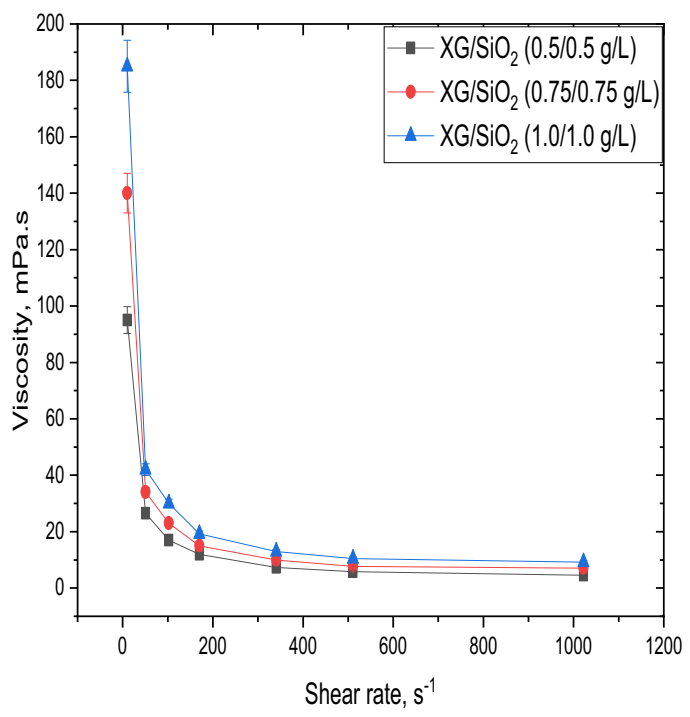

(b)

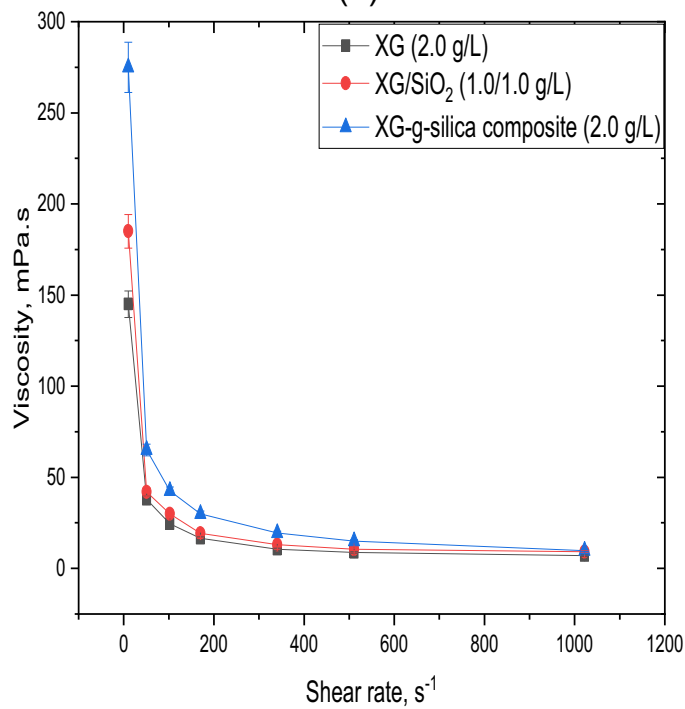

(d)

Fig. 3. Effect of the shearing rate on the apparent viscosity of (a) XG-g-silica composite; (b) physical XG/SiO 2 mixture; (c) xanthan gum (XG) polymer; and (d) comparison of three cases at a concentration of $2.0 \mathrm{~g} / \mathrm{L}$.

Table 2. Flow consistency and flow behavior coefficients.

\begin{tabular}{lcccc}
\hline Fluid & $a\left(\mathrm{~Pa} \mathrm{~s}^{-\mathrm{n}}\right)$ & $n$ & $R^{2}$ & Adj. $R^{2}$ \\
\hline $\mathrm{XG}$ & 890.00 & 0.761 & 0.9977 & 0.9973 \\
$\mathrm{XG} / \mathrm{SiO}_{2}$ & 1259.82 & 0.789 & 0.9958 & 0.9950 \\
XG-g-silica composite & 1865.81 & 0.797 & 0.9983 & 0.9979 \\
\hline
\end{tabular}

concentration of $2 \mathrm{~g} / \mathrm{L}$ and salinity of $20.0 \mathrm{~g} / \mathrm{L}$. In the case of $\mathrm{XG} / \mathrm{SiO}_{2}$ physical mixture, a charge neutralization occurs between negatively charged silica nanoparticles and positively charged cations in the saline solution, which reduce the electrostatic repulsion within polymer chains. Moreover higher surface area of silica nanoparticles allows adsorption of polymer chains on its surface forming a tough hybrid network with reduced electrostatic repulsion (Hu et al., 2018). On the other hand, XG-g-silica composite yields a boosted viscosity rather than $\mathrm{XG}$ and $\mathrm{XG} / \mathrm{SiO}_{2}$ due to the formation of an intramolecular association between silanol groups $\left(\mathrm{Si}_{-}-\mathrm{O}^{-}\right)$and formation water cations, so reduce cations competition to attack polymer chain (Maghzi et al., 2014). Moreover, insertion of silica through polymer chains form crosslinked network structure with large hydrodynamic volume (i.e., silica act as a crosslinking agent) which prohibit curling and coiling of polymer chains by salt addition (Yang-Chuan et al., 2008). 



Concentration $=0.75: 0.75 \mathrm{gl}$



Concentration $=2.0 \mathrm{gll}$


(a)

(b)
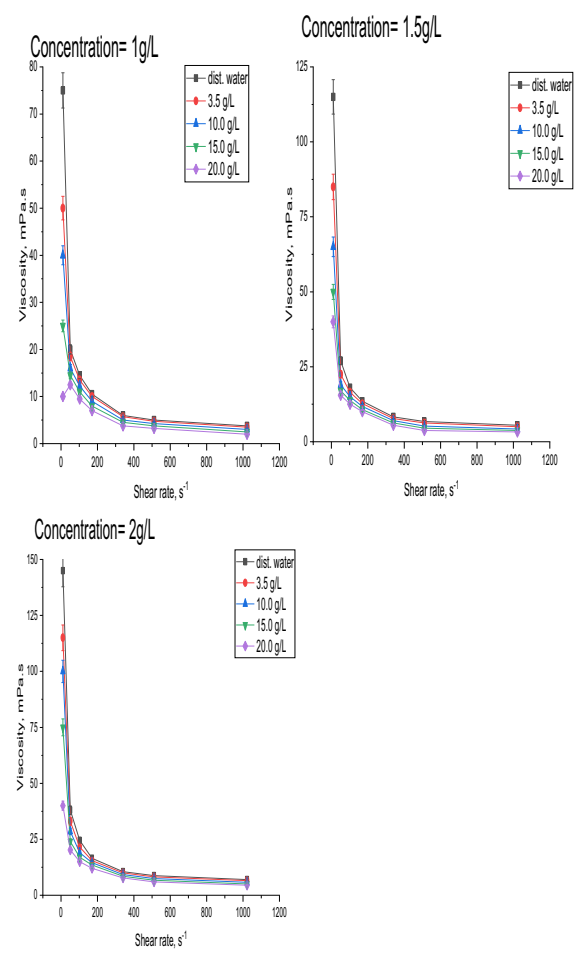

(c)

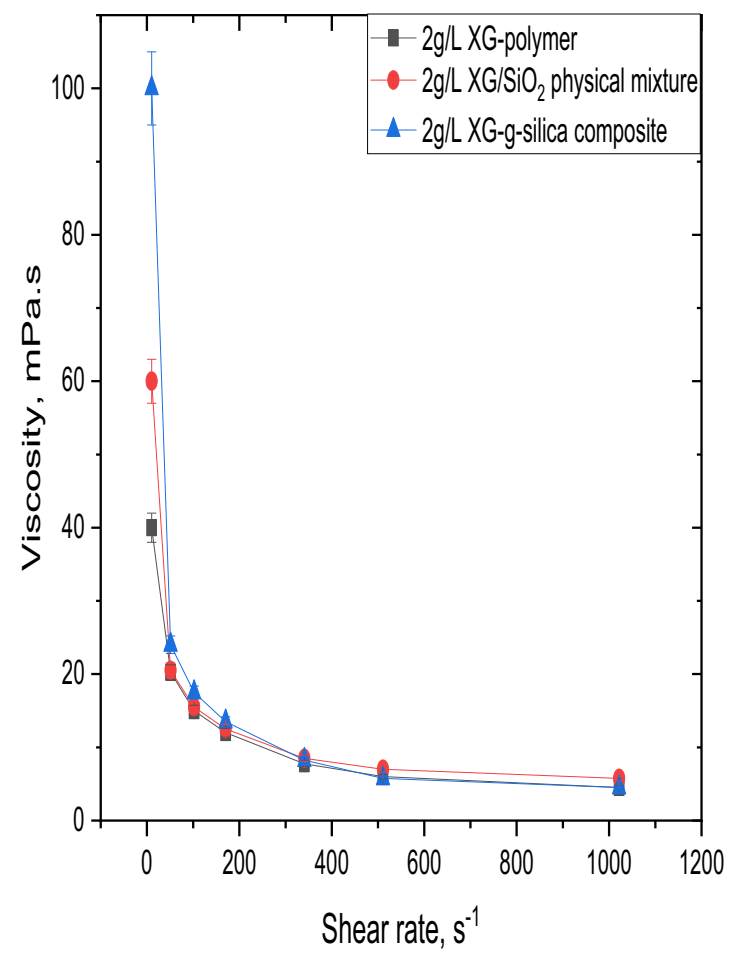

(d)

Fig. 4. Effect of salinity on displacing fluids. (a) XG-g-silica composite; (b) XG/ $\mathrm{SiO}_{2}$ physical mixture; (c) XG-polymer; and (d) comparison of three injected fluids at concentration $=2 \mathrm{~g} / \mathrm{L}$ and salinity $=20 \mathrm{~g} / \mathrm{L}$. 

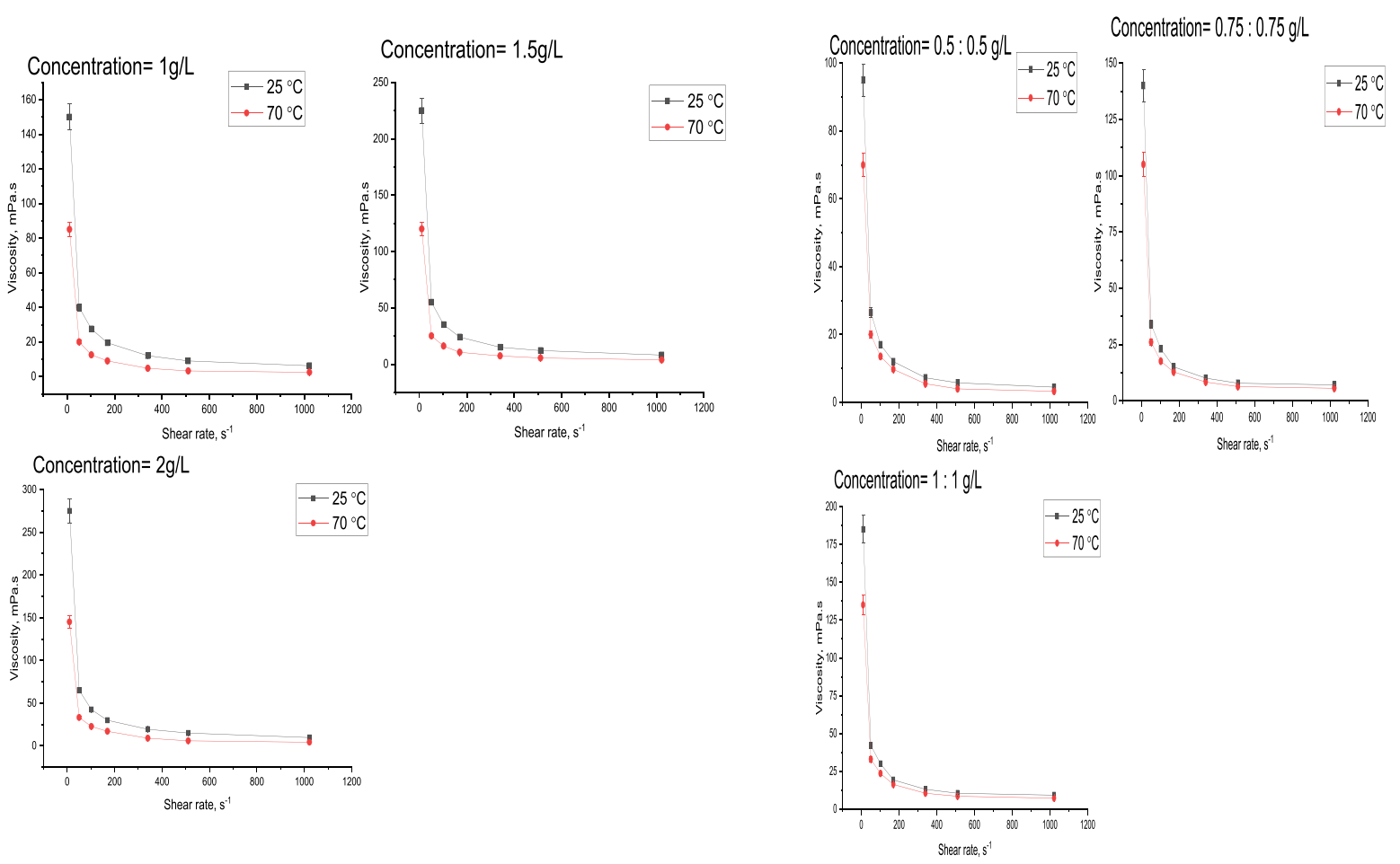

(a)

(b)

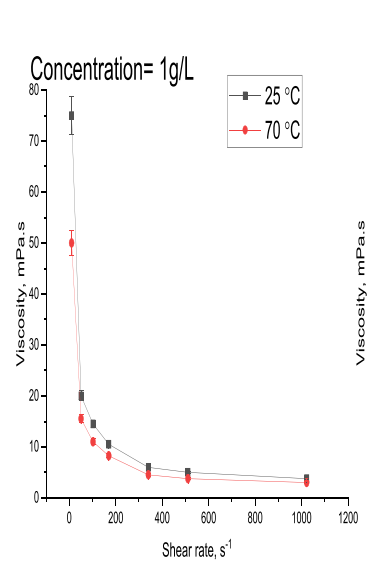

\section{Concentration $=1.5 \mathrm{gl}$}

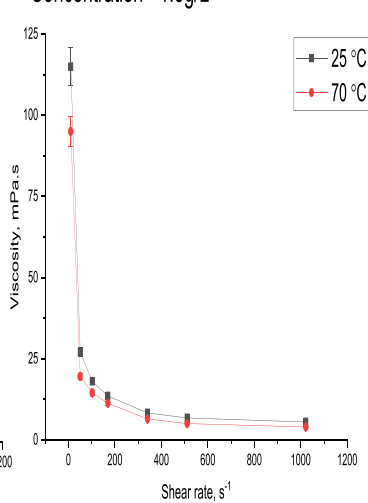

Concentration= 2gll
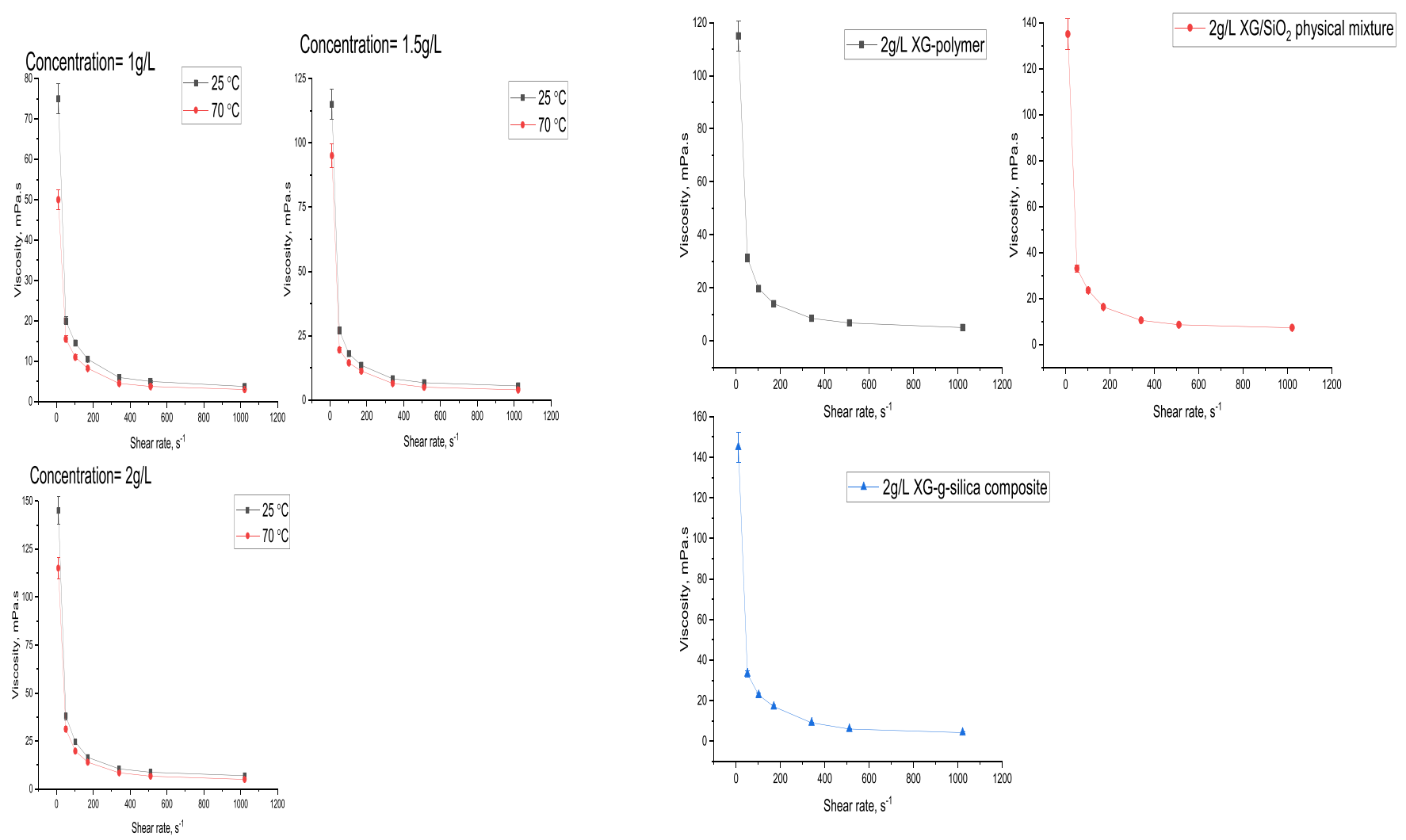

(c)

(d)

Fig. 5. Effect of temperature on displacing fluids. (a) XG-g-silica composite; (b) XG/ $\mathrm{SiO}_{2}$ physical mixture; (c) XG-polymer; and (d) comparison of three injected fluids at concentration $=2 \mathrm{~g} / \mathrm{L}$ and temperature $=70{ }^{\circ} \mathrm{C}$. 
Table 3. Flooding conditions and oil recovery by XG, XG/SiO 2 , and XG-g-silica.

\begin{tabular}{|c|c|c|c|c|c|c|c|c|c|c|c|c|c|c|c|}
\hline \multirow[t]{2}{*}{ \# Core } & \multirow[t]{2}{*}{$\begin{array}{l}\text { Injected } \\
\text { fluid }\end{array}$} & \multirow{2}{*}{$\begin{array}{l}\text { Slug } \\
\text { conc. } \\
(\mathrm{g} / \mathrm{L})\end{array}$} & \multirow{2}{*}{$\begin{array}{l}\text { Slug } \\
\text { conc. } \\
(\mathrm{lb})\end{array}$} & \multirow[t]{2}{*}{$\begin{array}{l}\text { Slug size } \\
(\% \mathrm{PV})\end{array}$} & \multirow[t]{2}{*}{$\begin{array}{c}V_{\mathrm{p}} \\
(\mathrm{cc})\end{array}$} & \multirow[t]{2}{*}{$\begin{array}{l}V_{\mathrm{oi}} \\
(\mathrm{cc})\end{array}$} & \multirow[t]{2}{*}{$\begin{array}{l}V_{\mathrm{wc}} \\
(\mathrm{cc})\end{array}$} & \multirow[t]{2}{*}{$\begin{array}{l}V_{\text {or }} \\
(\mathrm{cc})\end{array}$} & \multicolumn{3}{|c|}{$\begin{array}{c}\text { Saturation } \\
(\% \mathrm{PV})\end{array}$} & \multirow{2}{*}{$\begin{array}{c}\text { Recovered } \\
\text { Oil } \\
\text { (cc) }\end{array}$} & \multirow{2}{*}{$\begin{array}{c}\text { Recovered } \\
\text { Oil } \\
\times 10^{-5} \mathrm{bbl}\end{array}$} & \multirow{2}{*}{$\begin{array}{c}\text { Oil } \\
\text { recovery } \\
(\% \text { OOIP })\end{array}$} & \multirow{2}{*}{$\begin{array}{c}\text { Slug } \\
\text { efficiency } \\
\times 10^{-4} \\
(\mathrm{lb} / \mathrm{bbl} \text { oil })\end{array}$} \\
\hline & & & & & & & & & $S_{\mathrm{oi}}$ & $S_{\mathrm{wc}}$ & $S_{\text {or }}$ & & & & \\
\hline $2 \mathrm{~F}$ & Brine & 0 & 0.00 & 0.00 & 15.34 & 10.49 & 4.85 & 4.40 & 68.40 & 31.60 & 28.70 & 6.01 & 3.78 & 57.28 & 0.00 \\
\hline $4 \mathrm{p}$ & XG-polymer & 1 & 0.0022 & 55.01 & 18.18 & 11.60 & 6.58 & 4.60 & 63.80 & 36.20 & 25.30 & 7.01 & 4.41 & 60.40 & 4.99 \\
\hline $1 \mathrm{~F}$ & Physical & 1 & 0.0022 & 62.39 & 16.03 & 10.71 & 5.32 & 2.69 & 66.80 & 33.20 & 16.80 & 8.00 & 5.03 & 74.72 & 4.37 \\
\hline $3 \mathrm{P}$ & $\left(\mathrm{XG} / \mathrm{SiO}_{2}\right)$ & 1.5 & 0.0033 & 82.77 & 18.12 & 11.60 & 6.52 & 1.70 & 64.00 & 36.00 & 9.40 & 9.90 & 6.23 & 85.36 & 5.30 \\
\hline $1 \mathrm{P}$ & & 2 & 0.0044 & 115.77 & 17.28 & 11.00 & 6.27 & 3.09 & 63.70 & 36.30 & 17.90 & 7.90 & 4.97 & 71.79 & 8.85 \\
\hline $5 \mathrm{P}$ & XG-g-silica & 1 & 0.0022 & 64.4 & 15.53 & 10.29 & 5.23 & 1.34 & 66.30 & 33.70 & 8.60 & 8.97 & 5.64 & 87.14 & 3.90 \\
\hline
\end{tabular}

\subsubsection{Thermal degradation}

Thermal degradation of the three displacing fluids estimated by measuring solution viscosity at different shear rates and two temperatures $\left(25^{\circ} \mathrm{C}\right.$ and $\left.70{ }^{\circ} \mathrm{C}\right)$ as displayed in Figure 5 . The results indicate that viscosity reduction in case of $\mathrm{XG} / \mathrm{SiO}_{2}$ and $\mathrm{XG}$-g-silica composite due to high temperature was not significant as compared with the $\mathrm{XG}$ polymer at the same temperature. For more illustration, $\mathrm{XG}$-g-silica and $\mathrm{XG} / \mathrm{SiO}_{2}$ at $70{ }^{\circ} \mathrm{C}$ and $60 \mathrm{~s}^{-1}$ yield viscosity values of 23.5 and $19.75 \mathrm{mPa}$ s respectively, while xanthan gum viscosity equals $12.5 \mathrm{mPa}$. This higher thermal resistance of XG-g-silica composite resort to the generation of an intramolecular association between silanol group $(\mathrm{Si}-\mathrm{OH})$ and formation water cations, in addition to insertion of silica through polymer backbone which gives rise to reinforced three-dimensional hybrid network ( $\mathrm{Hu}$ et al., 2018). While $\mathrm{XG} / \mathrm{SiO}_{2}$ exhibit reasonable heat resistance due to the enrichment of endothermic intramolecular interaction with temperature increasing (El-Hoshoudy et al., 2016; Ye et al., 2013). Moreover, the formation of hydrogen-bonding between silanol groups $(\mathrm{Si}-\mathrm{OH})$ and carbonyl groups $(\mathrm{C}=\mathrm{O})$ (Hu et al., 2018; Maurya and Mandal, 2016) of ester in xanthan gum form compacted, rough structure which can resist high salinity and temperature. These observations are in great compliance with Giraldo et al. (2013) who proved that $\mathrm{SiO}_{2}$ nanoparticles can enhance the thermal resistance and mitigate the polymer decomposition by high temperature.

\subsection{Core flooding tests}

Core flooding conducted through three phases at a salinity of $20 \mathrm{~g} / \mathrm{L}$ and $25^{\circ} \mathrm{C}$. The 10 cores were flooded with different concentration of xanthan gum, XG-g-silica composites, and $\left(\mathrm{XG} / \mathrm{SiO}_{2}\right)$ physical mixture to obtain the optimum concentration which yields the maximum oil recovery. Cumulative oil recovery related to injected pore volumes of the three fluids are summarized in Table 3 and Figure 6. It's apparent that maximum recovery in case of XG and
XG-g-silica composite achieved at concentration = $2.0 \mathrm{~g} / \mathrm{L}$, while in case of $\mathrm{XG} / \mathrm{SiO}_{2}$, the maximum recovery achieved at $1.5 \mathrm{~g} / \mathrm{L}$ after that recovery factor decreased. This may be justified according to the following interpretation. In the case of XG-polymer, increasing of slug concentration increases the flooded solution viscosity, which in turn enhances sweeping efficiency and oil recovery factor (El-Hoshoudy, 2019; El-hoshoudy et al., 2019). Moreover, it is apparent that oil recovery increase by $6.14 \%$ with increasing the xanthan gum concentration from 1.0 to $1.5 \mathrm{~g} / \mathrm{L}$ while the oil recovery only increased by $2.77 \%$ when the concentration of polymer increases from $1.5 \mathrm{~g} / \mathrm{L}$ to $2.0 \mathrm{~g} / \mathrm{L}$. This indicates that the higher the polymer concentration, the higher the oil recovery, but the increase in the oil recovery reduces with further increase in the polymer concentration owing to polymer retention and blockage. These results match with Wang et al. (2012) who showed that additional oil recovery can be obtained with a high concentration of polymer solutions. In the case of $\left(\mathrm{XG} / \mathrm{SiO}_{2}\right)$ decreasing of recovery factor at slug concentration $>\left(0.75 \mathrm{~g} / \mathrm{L}\right.$ of $\mathrm{XG}+0.75 \mathrm{~g} / \mathrm{L}$ of $\left.\mathrm{SiO}_{2}\right)$ resort to an accumulation of $\mathrm{SiO}_{2}$ nanoparticles at higher concentrations, which in turn cause clogging of the pore throats and permeability reduction. These results are highly compatible with Hendraningrat et al. (2013) who stated that increasing hydrophilic nanoparticles concentration adversely affects the oil recovery owing to impairment of the reservoir rock permeability. In the case of XG-g-silica composite, achieving of maximum recovery at $2.0 \mathrm{~g} / \mathrm{L}$ reveals that silica uniformly distributed in the polymer matrix, and would not be precipitated during core flooding. The mobility control of three displacing fluids over formation water was quantified by $R_{\mathrm{f}}$ and $R_{\mathrm{ff}}$ is provided in Supporting Information.

\subsection{Relative permeability curves and rock wettability}

Since rock wettability influence relative permeability curves and capillary pressure which in turn control the recovery factor (Bera and Belhaj, 2016). In this study, we evaluate 



(a)



(b)

Fig. 6. Cumulative oil recovery of displacing fluids. (a) Cumulative oil recovery of the three injected fluids relative to injected pore volume; (b) comparison of cumulative oil recovery of the three injected fluids at a concentration of $2 \mathrm{~g} / \mathrm{L}$. the rock wettability by monitoring the oil and water relative permeabilities $\left(K_{\mathrm{ro}}\right.$ and $\left.K_{\mathrm{rw}}\right)$ during the core displacement (Ahmadi and Shadizadeh, 2018) as displayed in Figure 7a. It's apparent that the cross-points of the water and oil relative permeability curves in case of XG, XG/ $\mathrm{SiO}_{2}$, and XG-g-silica composite are observed at $S_{\mathrm{w}} @$ $K_{\mathrm{ro}}=K_{\mathrm{rw}}=0.60401,0.685$, and 0.715 respectively. This behavior proves that silica insertion increase water wettability from weak water wet to strong water wet, and this is in great compliance with Al Matroushi et al. (2015) and Moradi et al. (2015), who stated that "silica nanoparticles act as water wetting agents for sandstone rock, so increase recovered oil amount". Increasing of water-wet characteristics by silica addition resort to hydrophilic characters of silica with spreading hydroxyl $(-\mathrm{OH})$ groups on its surface so can form hydrogen bridging with formation water, which in turn construct hydrophilic coating layer on the rock surface (Zargartalebi et al., 2015). Moreover, nanomaterials form three-dimensional structure at the interface of rock/oil/brine, which gives rise to structural disjoining pressure, so nano-fluids act as a wedge-like knife detaching the oil from the rock surface (Bera and Belhaj, 2016; El-Hoshoudy et al., 2016; Wasan and Nikolov, 2003) and increase recovery factor. Since changing wettability from oil wet to water wet improves the recovery factor during water flooding (Ahmadi and Shadizadeh, 2018) so the XG-g-silica and XG/ $/ \mathrm{SiO}_{2}$ can be considered as a good EOR alternative. Moreover, the fractional flow curves of the three displacing fluids at a concentration of $2.0 \mathrm{~g} / \mathrm{L}$ as shown in Figure 7b, indicate that XG-g-silica solution is more shifted to the right side which means high average water saturation, more efficient displacement, and a lesser amount of residual oil $\left(S_{\mathrm{or}}\right)$ (Attia, 2005; Sayyouh et al., 1993). Results of displacement efficiency $\left(E_{\mathrm{D}}\right)$ and average water saturation are calculated according to equation (4) and summarized in Table 4:

$$
E_{\mathrm{D}}=\frac{\overline{S_{\mathrm{w}}}-S_{\mathrm{wi}}}{1-S_{\mathrm{wi}}}
$$

Figure $7 \mathrm{c}$ shows the relation between relative permeability ratio $\left(K_{\mathrm{ro}} / K_{\mathrm{rw}}\right)$ and water saturation $\left(S_{\mathrm{w}}\right)$ for different injected fluids at concentration of $2.0 \mathrm{~g} / \mathrm{L}$. It is observed that the main portion of the relative permeability ratio saturation curve is quite linear. The fitting line of the middle part after neglecting the inlet and outlet of curve yields empirical correlation (Eq. (5)):

$$
\frac{K_{\mathrm{ro}}}{K_{\mathrm{rw}}}=a e^{-b S_{\mathrm{w}}} .
$$

It is noticed that the values of " $b$ " are relatively constant in the three different injected fluids, but values of " $a$ " are different as shown in Table 4. By increasing the value of " $a$ " at any water saturation, the fractional flow of water decreases, hence the displacement efficiency increases. Therefore, XG-g-silica composite yields displacement efficiency more than $\mathrm{XG} / \mathrm{SiO}_{2}$ physical mixture and XG-polymer as exhibited in Figures 7b and 7c. Figure 7d and Table 5 show the relation between water saturation at cross points and residual oil saturation. The results 


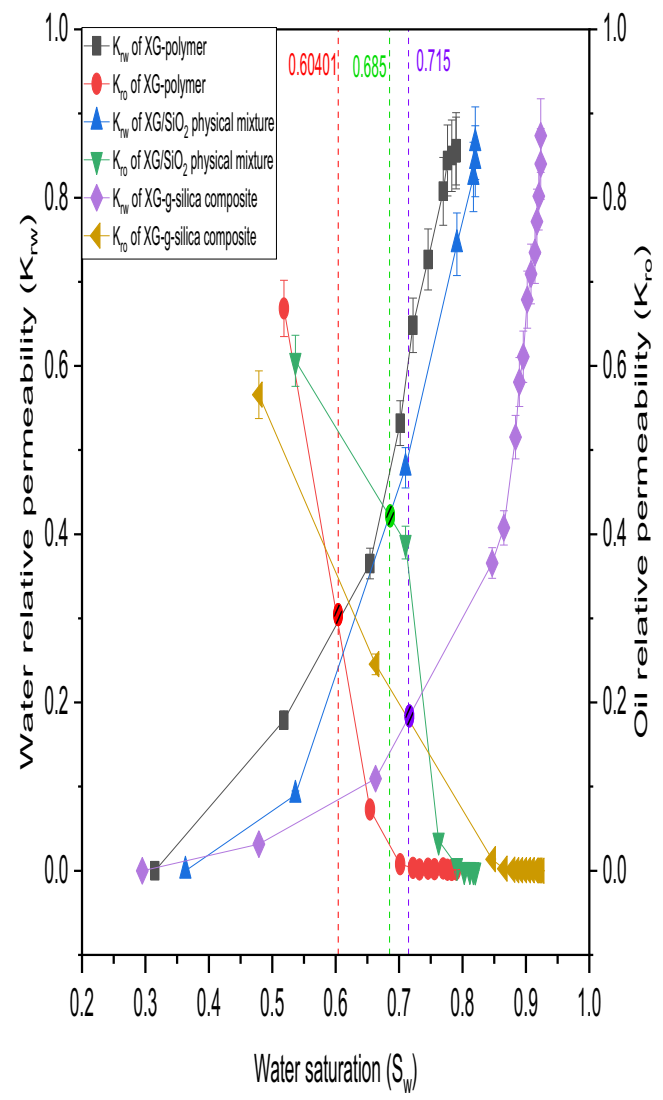

(a)

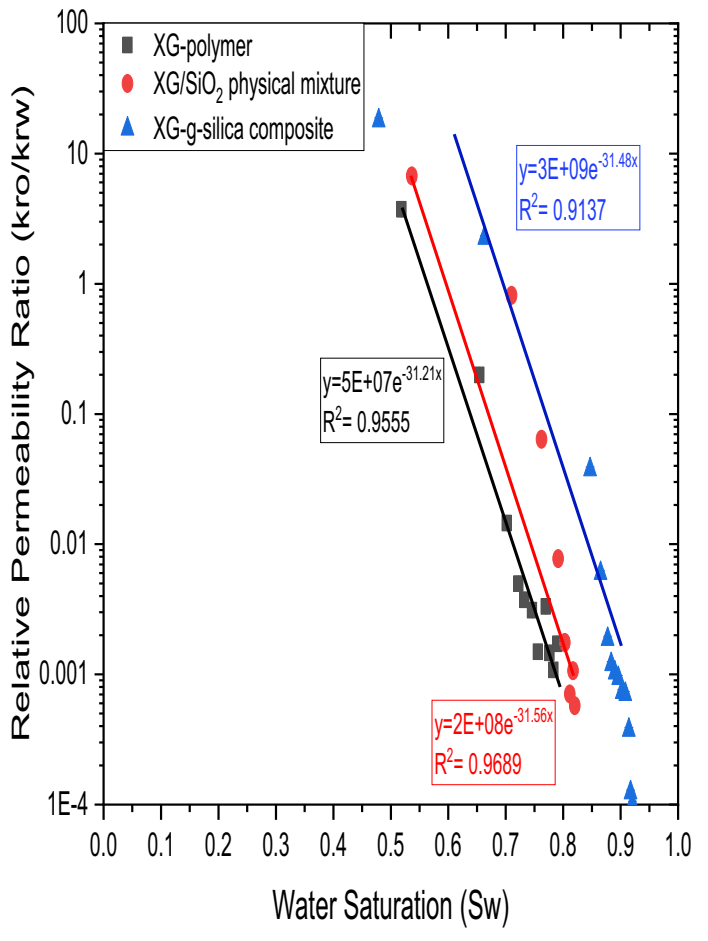

(c)

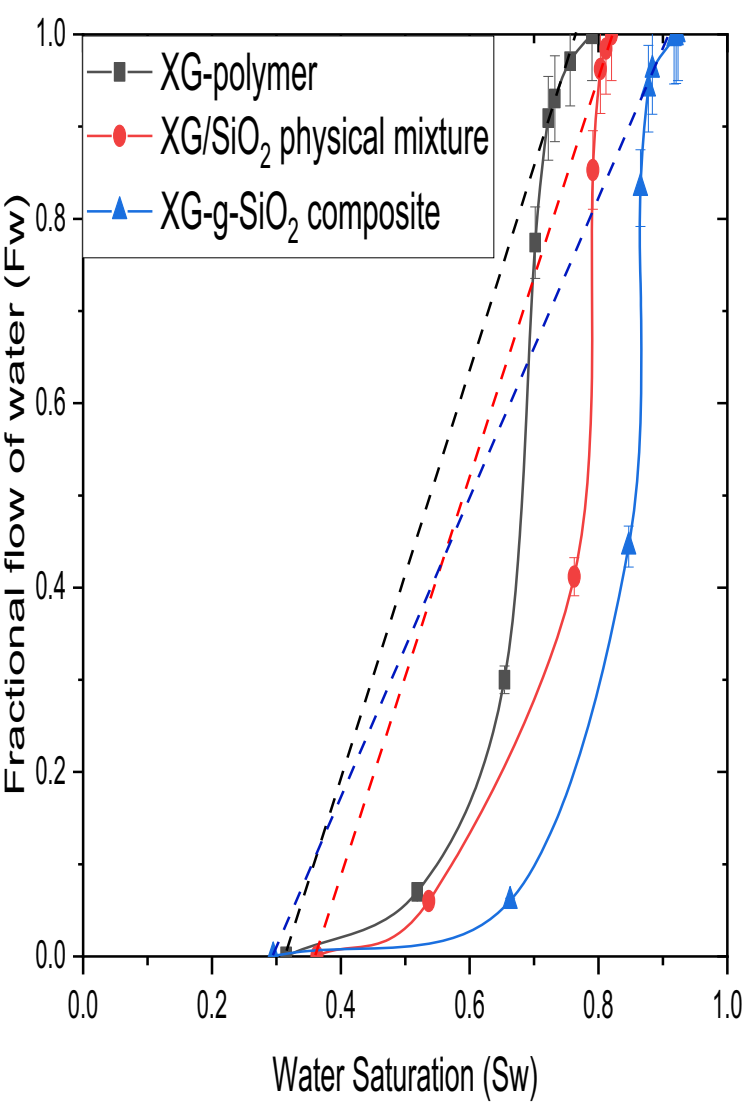

(b)

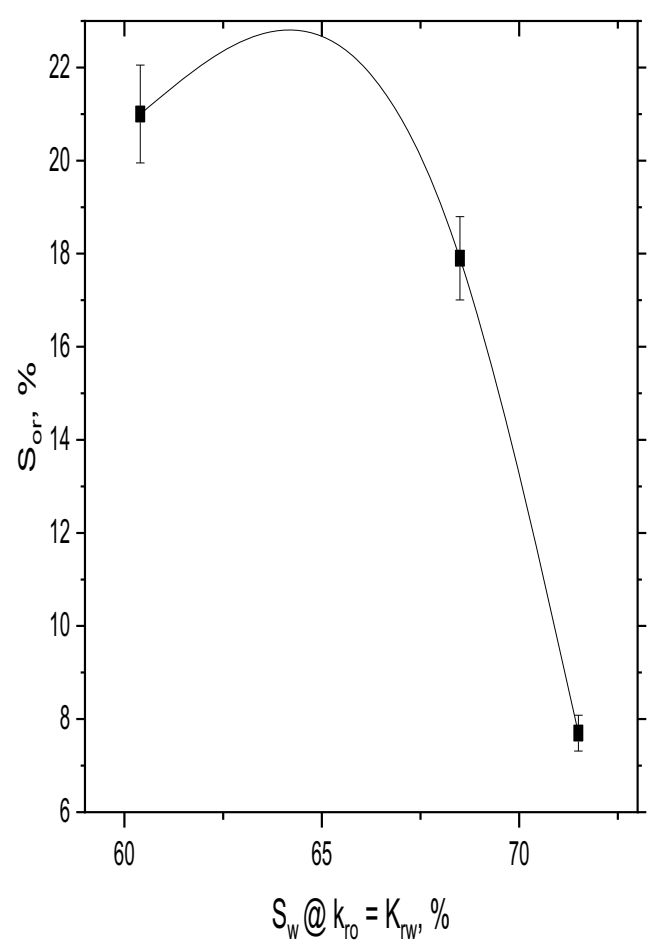

(d)

Fig. 7. Curves of three injected fluids. (a) Oil and water relative permeability curves; (b) fractional flow curves; (c) relative permeability ratio saturation curve; (d) water saturation at cross points versus residual oil saturation. 
Table 4. Displacement efficiency and average water saturation.

\begin{tabular}{|c|c|c|c|c|c|c|}
\hline Injected fluid & $a$ (intercept) & $b$ (slope) & $\begin{array}{c}F_{\mathrm{w}} \text { at certain } \\
\text { water saturation } \\
\quad\left(S_{\mathrm{w}}=0.4\right)\end{array}$ & $\begin{array}{l}\text { Recovery } \\
\text { factor, } \\
\% \text { OOIP } \\
\end{array}$ & $\overline{S_{\mathrm{w}}}$ & $\begin{array}{c}\text { Displacement } \\
\text { efficiency } \\
\text { (ED), \% } \\
\end{array}$ \\
\hline XG-polymer & $5 \times 10^{7}$ & 31.21 & $2.63 \times 10^{-4}$ & 69.31 & 0.76 & 65 \\
\hline $\mathrm{XG} / \mathrm{SiO}_{2}$ physical mixture & $2 \times 10^{8}$ & 31.56 & $6.80 \times 10^{-5}$ & 71.79 & 0.818 & 71.43 \\
\hline XG-g-silica composite & $3 \times 10^{9}$ & 31.48 & $2.93 \times 10^{-6}$ & 89.13 & 0.895 & 85.11 \\
\hline
\end{tabular}

Table 5. Relative permeability curves and wettability alteration.

\begin{tabular}{lcccc}
\hline Injected fluid & $S_{\mathrm{w}} @\left(k_{\mathrm{ro}}=k_{\mathrm{rw}}\right)$ & $S_{\mathrm{wc}}$ & $S_{\mathrm{or}}$ & Error bar \\
\hline $\mathrm{XG}-$ polymer & 60.401 & 31.50 & 21.00 & 1.05 \\
$\mathrm{XG} / \mathrm{SiO}_{2}$ physical mixture & 68.5 & 36.30 & 17.90 & 0.895 \\
XG-g-silica composite & 71.5 & 29.50 & 7.70 & 0.385 \\
\hline
\end{tabular}

showed that residual oil saturation decreased with increasing the water saturation at cross points which means the rock wettability had been changed from oilwet to water-wet and from weak water-wet to strong water-wet due to the presence of silica nano-particles.

\section{Conclusion}

Modification of biopolymer precursors is an efficient method to boost their ability in EOR processing at high ionic strength and temperature. In this study, $\mathrm{SiO}_{2}$ successfully synthesized and characterized, then xanthan gum grafted with vinylsilane derivative via free radical initiation. The response of the displacing fluids to mechanical, ionic and thermal degradation investigated at the high shearing action and harsh reservoir conditions. A comparative evaluation of xanthan gum, XG/ $\mathrm{SiO}_{2}$ physical mixture, and XG-g-silica composite as flooding agents performed on outcrop sandstone cores. Moreover, wettability alteration is measured by relative permeability saturation curve. Based on these observations, the following conclusions can be drawn:

- The mixing or grafting of silica derivatives greatly improves the rheological properties of xanthan gum to withstand higher salinity and temperature.

- Relative permeability curves and fractional flow curves indicate that the presence of silica precursors modify the wetting action of cores to more waterwet and improve displacement efficiency which in turn enhance the oil recovery.

- The cumulative oil recovery increased by increasing xanthan gum fluid concentration and the maximum oil recovery is achieved at $2 \mathrm{~g} / \mathrm{L}$.

- Oil recovery increases by increasing the concentration of $\mathrm{XG} / \mathrm{SiO}_{2}$ physical mixture up to $1.5 \mathrm{~g} / \mathrm{L}$, but with further increasing the concentration of $\mathrm{XG} / \mathrm{SiO}_{2}$ physical mixture, the amount of oil will decrease.
- XG-g-silica composite can be considered as a reasonable agent to enhance the oil recovery where has a great effect on interfacial tension reduction and wettability alteration.

\section{Supplementary material}

Supplementary material is available at https://ogst. ifpenergiesnouvelles.fr/10.2516/ogst/2020004/olm

Table S1. Ionic composition of saline solutions used in rheological and flooding tests.

Table S2. Physical properties and dimensions of core samples.

Table S3. Pressure differential profiles of the three displacing fluids (XG, XG/SiO ${ }_{2}$, and XG-g-silica composite).

Fig. S1. Fourier Transformation spectroscopy of $\mathrm{SiO}_{2}$, and XG-g-silica composite.

Fig. S2. ${ }^{1} \mathrm{H}$ NMR spectra (a) Xanthan gum and (b) XGg-silica composite respectively.

Fig. S3. Thermal gravimetric analysis of $\mathrm{SiO}_{2}$, Xanthan gum, and XG-g-silica composite.

Fig. S4. TEM photographing of (a) $\mathrm{SiO}_{2}$, and (b) XGg-silica composite.

Scheme S1. Formation reaction of XG-g-silica composite.

\section{References}

AfzaliTabar M., Alaei M., Bazmi M., Khojasteh R.R., Koolivand-Salooki M., Motiee F., Rashidi A. (2017) Facile and economical preparation method of nanoporous graphene/silica nanohybrid and evaluation of its Pickering emulsion properties for Chemical Enhanced oil Recovery (C-EOR), Fuel 206, 453-466.

Ahmadi M.A., Shadizadeh S.R. (2018) Spotlight on the new natural surfactant flooding in carbonate rock samples in low salinity condition, Sci. Rep. 8, 1, 10985. 
Al Matroushi M., Pourafshary P., Al Wahaibi Y. (2015) Possibility of nanofluid/gas alternating injection as an EOR method in an oil field, Paper Presented at the Abu Dhabi International Petroleum Exhibition and Conference, 9-12 November, Abu Dhabi, UAE.

Attia A.M. (2005) Effects of petrophysical rock properties on tortuosity factor, J. Pet. Sci. Eng. 48, 3-4, 185-198.

Badwaik H.R., Sakure K., Alexander A., Dhongade H., Tripathi D.K. (2016) Synthesis and characterisation of poly (acryalamide) grafted carboxymethyl xanthan gum copolymer, Int. J. Biol. Macromol. 85, 361-369.

Bai Y., Shang X., Wang Z., Zhao X. (2018) Experimental study on hydrophobically associating hydroxyethyl cellulose flooding system for enhanced oil recovery, Energy Fuels 32, 6, 6713-6725.

Bera A., Belhaj H. (2016) Application of nanotechnology by means of nanoparticles and nanodispersions in oil recovery-A comprehensive review, J. Nat. Gas Sci. Eng. 34, 1284-1309.

Boggs S. Jr, Boggs S. (2009) Petrology of sedimentary rocks, Cambridge University Press, Cambridge, UK.

Chiantore O. (2005) Mark-Houwink relationship, Encycl. Chromatogr. 2, 1019.

El-Hoshoudy A. (2018a) Quaternary ammonium based surfmerco-acrylamide polymers for altering carbonate rock wettability during water flooding, J. Mol. Liq. 250, 35-43.

El-Hoshoudy A. (2018b) Synthesis of acryloylated starch-g-poly acrylates crosslinked polymer functionalized by emulsified vinyltrimethylsilane derivative as a novel EOR agent for severe polymer flooding strategy, Int. J. Biol. Macromol. 123, 124-132.

El-Hoshoudy A. (2019) Synthesis of acryloylated starch-g-poly acrylates crosslinked polymer functionalized by emulsified vinyltrimethylsilane derivative as a novel EOR agent for severe polymer flooding strategy, Int. J. Biol. Macromol. 123, 124-132.

El-Hoshoudy A., Desouky S. (2018) Synthesis and evaluation of acryloylated starch-g-poly (Acrylamide/Vinylmethacrylate/ 1-Vinyl-2-pyrrolidone) crosslinked terpolymer functionalized by dimethylphenylvinylsilane derivative as a novel polymerflooding agent, Int. J. Biol. Macromol. 116, 434-442.

El-Hoshoudy A., Desouky S., Attia A. (2018) Synthesis of starch functionalized sulfonic acid co-imidazolium/silica composite for improving oil recovery through chemical flooding technologies, Int. J. Biol. Macromol. 118, 1614-1626.

El-Hoshoudy A., Desouky S., Betiha M., Alsabagh A. (2016) Use of 1-vinyl imidazole based surfmers for preparation of polyacrylamide- $\mathrm{SiO}_{2}$ nanocomposite through aza-Michael addition copolymerization reaction for rock wettability alteration, Fuel 170, 161-175.

El-hoshoudy A., Mohammedy M., Ramzi M., Desouky S., Attia A. (2019) Experimental, modeling and simulation investigations of a novel surfmer-co-poly acrylates crosslinked hydrogels for water shut-off and improved oil recovery, J. Mol. Liq. 277, 142-156.

Giraldo J., Benjumea P., Lopera S., Cortés F.B., Ruiz M.A. (2013) Wettability alteration of sandstone cores by aluminabased nanofluids, Energy Fuels 27, 7, 3659-3665.

Goldberg A., Hohenstein W., Mark H. (1947) Intrinsic viscositymolecular weight relationship for polystyrene, J. Polym. Sci. 2, 5, 503-510.

Hendraningrat L., Engeset B., Suwarno S., Li S., Torsæter O. (2013) Laboratory investigation of porosity and permeability impairment in Berea sandstones due to hydrophilic nanoparticle retention, Paper Presented at the Paper
SCA2013-062 Presented at the International Symposium of the Society of Core Analysts Held in Napa Valley, California, $U S A$.

Hu X., Ke Y., Zhao Y., Lu S., Yu C., Peng F. (2018) Synthesis and characterization of a $\beta$-cyclodextrin modified polyacrylamide and its rheological properties by hybriding with silica nanoparticles, Coll. Surf. A: Physicochem. Eng. Asp. 548, $10-18$.

Hu Z., Haruna M., Gao H., Nourafkan E., Wen D. (2017) Rheological properties of partially hydrolyzed polyacrylamide seeded by nanoparticles, Ind. Eng. Chem. Res. 56, 12, 34563463.

Kang X., Zhang J. (2013) Surfactant polymer (SP) flooding pilot test on offshore heavy oil field in Bohai Bay, China, Paper Presented at the SPE Enhanced Oil Recovery Conference, 2-4 July, Kuala Lumpur, Malaysia.

Kovalchuk T., Sfihi H., Korchev A., Kovalenko A., Ilin V., Zaitsev V., Fraissard J. (2005) Synthesis, structure, and acidic properties of MCM-41 functionalized with phosphate and titanium phosphate groups, J. Phys. Chem. B 109, 29, 13948-13956.

Kumar A., Sharma S., Srivastava A., Kumar R. (2017) Synthesis of xanthan gum graft copolymer and its application for controlled release of highly water soluble Levofloxacin drug in aqueous medium, Carbohydr. Polym. 171, 211-219.

Kumar R.S., Sharma T. (2018) Stability and rheological properties of nanofluids stabilized by $\mathrm{SiO}_{2}$ nanoparticles and $\mathrm{SiO}_{2}-\mathrm{TiO}_{2}$ nanocomposites for oilfield applications, Coll. Surf. A: Physicochem. Eng. Asp. 539, 171-183.

Li S., Gou S., Chen X., Duan M. (2018) Comb-shaped polyzwitterion with surface-activity obtained via N-maleoyl chitosan-modified HPAM for displacement of residual oil, New J. Chem. 42, 9, 6848-6857.

Liu R., Pu W., Sheng J.J., Du D. (2017) Star-like hydrophobically associative polyacrylamide for enhanced oil recovery: Comprehensive properties in harsh reservoir conditions, J. Taiwan Inst. Chem. Eng. 80, 639-649.

Maerker J.M. (1975) Shear degradation of partially hydrolyzed polyacrylamide solutions, Soc. Pet. Eng. J. 15, 04, 311-322.

Maghzi A., Kharrat R., Mohebbi A., Ghazanfari M.H. (2014) The impact of silica nanoparticles on the performance of polymer solution in presence of salts in polymer flooding for heavy oil recovery, Fuel 123, 123-132.

Maghzi A., Mohebbi A., Kharrat R., Ghazanfari M. (2013) An experimental investigation of silica nanoparticles effect on the rheological behavior of polyacrylamide solution to enhance heavy oil recovery, Pet. Sci. Technol. 31, 5, 500-508.

Maurya N.K., Kushwaha P., Mandal A. (2017) Studies on interfacial and rheological properties of water soluble polymer grafted nanoparticle for application in enhanced oil recovery, J. Taiwan Inst. Chem. Eng. 70, 319-330.

Maurya N.K., Mandal A. (2016) Studies on behavior of suspension of silica nanoparticle in aqueous polyacrylamide solution for application in enhanced oil recovery, Pet. Sci. Technol. 34, 5, 429-436.

McGeary D., Carlson D.H., Plummer C.C. (2001) Physical geology, McGraw-Hill Science/Engineering/Math, New York, USA.

Moradi B., Pourafshary P., Jalali F., Mohammadi M., Emadi M. (2015) Experimental study of water-based nanofluid alternating gas injection as a novel enhanced oil-recovery method in oil-wet carbonate reservoirs, J. Nat. Gas Sci. Eng. 27, 64-73. 
Pandey S., Mishra S.B. (2011) Graft copolymerization of ethylacrylate onto xanthan gum, using potassium peroxydisulfate as an initiator, Int. J. Biol. Macromol. 49, 4, 527-535.

Porter S. (1987) Physical geology, John Wiley and Sons Inc., New York.

Pu W.-F., Liu R., Wang K.-Y., Li K.-X., Yan Z.-P., Li B., Zhao L. (2015) Water-soluble core-shell hyperbranched polymers for enhanced oil recovery, Ind. Eng. Chem. Res. 54, 3, 798-807.

Salehi M.B., Vasheghani-Farahani E., Sefti M.V., Moghadam A. M., Naderi H. (2014) Rheological and transport properties of sulfonated polyacrylamide hydrogels for water shutoff in porous media, Polym. Adv. Technol. 25, 4, 396-405.

Sayyouh M.H., Al-Blehed M.S., Attia A.M. (1993) The effect of alkaline and polymer additives on phase behaviour of surfactant-oil-brine system at high salinity conditions, Rev. Inst. Fr. Pét. 48, 4, 359-369.

Shamilov V., Babayev E., Kalbaliyeva E., Shamilov F. (2017) Polymer nanocomposites for enhanced oil recovery, Mater. Today: Proc. 4, S70-S74.

Stöber W., Fink A., Bohn E. (1968) Controlled growth of monodisperse silica spheres in the micron size range, J. Coll. Interface Sci. 26, 1, 62-69.

Suh I.-S., Herbst H., Schumpe A., Deckwer W.-D. (1990) The molecular weight of xanthan polysaccharide produced under oxygen limitation, Biotechnol. Lett. 12, 3, 201-206.

Wang L., Wang Y., Pu H., Zhang C., Yin D., Wang L. (2012) Study on high-concentration polymer flooding in Lamadian oilfield, Daqing, Paper Presented at the SPE EOR Conference at Oil and Gas West Asia, 16-18 April, Muscat, Oman.

Wang X., Zhang Y., Luo W., Elzatahry A.A., Cheng X., Alghamdi A., Zhao D. (2016) Synthesis of ordered mesoporous silica with tunable morphologies and pore sizes via a nonpolar solvent-assisted stober method, Chem. Mater. 28, 7, 2356-2362.

Wasan D.T., Nikolov A.D. (2003) Spreading of nanofluids on solids, Nature 423, 6936, 156.

Xu Y., Gao P., Yang M., Huang G., Wang B. (2011) Synthesis and aqueous solution properties of a novel nonionic, amphiphilic comb-type polyacrylamide, J. Macromol. Sci., Part B 50, 9, 1691-1704.

Yang-Chuan K., Guang-Yao W., Yi W. (2008) Preparation, morphology and properties of nanocomposites of polyacrylamide copolymers with monodisperse silica, Eur. Polym. J. 44, 8, 2448-2457.

Ye Z., Feng M., Gou S., Liu M., Huang Z., Liu T. (2013) Hydrophobically associating acrylamide-based copolymer for chemically enhanced oil recovery, J. Appl. Polym. Sci. 130, 4, 2901-2911.

Zargartalebi M., Kharrat R., Barati N. (2015) Enhancement of surfactant flooding performance by the use of silica nanoparticles, Fuel 143, 21-27.

Zhong L., Oostrom M., Truex M.J., Vermeul V.R., Szecsody J.E. (2013) Rheological behavior of xanthan gum solution related to shear thinning fluid delivery for subsurface remediation, J. Hazard. Mater. 244, 160-170. 